\title{
Erythroid Colony Growth in Congenital Hypoplastic Anemia
}

\author{
Melvin H. Freedman, Dominicx Amato, and E. Fred Saunders \\ with the technical assistance of WIIMA HidDLeston \\ From the Division of Hematology and Department of Pediatrics, The Hospital \\ for Sick Children and The University of Toronto, Toronto, Ontario, Canada M5G 1X8
}

A B S T R A C T Four children with congenital hypoplastic anemia (Diamond-Blackfan syndrome) and 30 control children with normal erythropoiesis were studied by a cell culture method in which human marrow, grown in a plasma clot, responds to added erythropoietin (EPO) with the appearance of discrete colonies of nucleated erythroid cells. The colonies arise from EPO-responsive stem cells and are not related to the number of morphologically identifiable marrow erythroids plated. Results of studies on control marrow indicated that without EPO there was little or no colony formation. Increasing EPO doses or nucleated marrow cells per culture resulted in a linear increase in colony numbers. The optimal EPO concentration of 2.5 $\mathrm{U} / \mathrm{ml}$ yielded a mean of $158 \pm 79$ colonies $/ 1 \times 10^{5} \mathrm{nu}-$ cleated cells on day 7 of incubation. Even in the absence of recognizable erythroids, marrows of all four patients with anemia grew erythroid colonies. Two patients on no therapy had decreased colony numbers. The other two, on prednisone, had normal numbers. Sera from patients did not inhibit colony formation from either autologous or control marrow. In contrast, serum from an adult with acquired pure red cell aplasia produced striking inhibition of colony growth. It appears that the red cell failure in this disorder is not due to an absence of erythroid stem cells, and a serum inhibitor to erythropoiesis as seen in the acquired disease is unlikely.

\section{INTRODUCTION}

Congenital hypoplastic anemia (Diamond-Blackfan syndrome, "erythrogenesis imperfecta," congenital pure red cell anemia) is an outstanding example of an isolated, chronic underproduction of one cell line. The condition is due to an error in hematologic development in which erythropoiesis is either profoundly diminished or completely absent. In the early months of life, a

Received for publication 14 February 1975 and in revised form 30 October 1975. progressive anemia develops, characterized by absent reticulocytosis and reduced marrow erythroid elements. About one-half of these children experience a complete remission when treated with corticosteroids (1). Since the serum erythropoietin (EPO) ${ }^{2}$ levels are consistently elevated (2), various etiological possibilities must be considered. The disorder could be due to absent or reduced erythroid progenitors or stem cells, decreased responsiveness of stem cells to EPO, the presence of an abnormal EPO, an "unfavorable" marrow microenvironment, or the presence of an inhibitor of erythropoiesis as seen in adults with acquired pure red cell aplasia (3-8).

To investigate the pathogenesis of this syndrome, we have used a tissue culture method in which marrow cells grown in a plasma clot respond to exogenous EPO with the appearance of discrete nucleated erythroid colonies (9). Each colony represents the differentiation of an erythroid progenitor or precursor $(9,10)$ and thus allows the study of earlier events in erythropoiesis than was heretofore possible in vitro.

\section{METHODS}

Patients. Four patients with congenital hypoplastic anemia were studied. Their clinical and hematological data are summarized in Table I. All fit the classic clinical description for this disorder. The only hematological abnormality was anemia due to failure of red cell production. The other cell lines were normal. Patients 1 and 4 had responded initially to daily prednisone with an increase in hemoglobin to normal; at the time of study, the dosage was reduced and they were anemic again. Patient 3 had been treated with prednisone for $2 \frac{1}{2} \mathrm{yr}$ during which the hemoglobin was normal. Because of growth failure, it was stopped before study and the hemoglobin fell, necessitating monthly transfusions. Patient 2, a sibling of patient 3 , had not received prednisone and required monthly transfusions.

Controls. Marrows from 30 other children were cultured for erythroid colonies. These children had marrow aspirates performed during investigations for malignancy, storage disease, and idiopathic thrombocytopenic purpura. Although not considered "normal" in the strict sense, and not a homogeneous population, all had normal hemoglobin con-

${ }^{1}$ Abbreviation used in this paper: EPO, erythropoietin. 
TABLE I

Clinical and Hematologic Data on Four Patients with Congenital Hypoplastic Anemia

\begin{tabular}{|c|c|c|c|c|}
\hline & Pt 1 & Pt 2 & Pt 3 & Pt 4 \\
\hline Age at diagnosis, mo & 2 & 2 & 1 & $3 \frac{1}{2}$ \\
\hline Age at study, $y r$ & 2 & $\frac{1}{2}$ & $2 \frac{1}{2}$ & 3 \\
\hline Hemoglobin, $\mathrm{g} / 100 \mathrm{ml}$ & 7.4 & 7.0 & 5.5 & 10.5 \\
\hline Reticulocytes, \% & 0.5 & 0.0 & 0.0 & 0.8 \\
\hline White blood cells, per $\mathrm{mm}^{3}$ & 4,500 & 8,700 & 6,900 & 7,700 \\
\hline$\%$ polymorphs & 50 & 20 & 42 & 40 \\
\hline \% lymphocytes & 40 & 75 & 48 & 55 \\
\hline$\%$ monocytes & 10 & 5 & 10 & 5 \\
\hline Platelets, per $\mathrm{mm}^{3}$ & 481,000 & 250,000 & 220,000 & 180,000 \\
\hline \multicolumn{5}{|l|}{ Marrow } \\
\hline$\%$ pronormoblasts & 4 & 0 & 0 & 2 \\
\hline$\%$ later nucleated $\mathrm{RBC}$ & 4 & 0 & 0 & 0 \\
\hline$\%$ granulocytic & 59 & 58 & 60 & 55 \\
\hline$\%$ other & 33 & 42 & 40 & 43 \\
\hline Cellularity & Normal & $\begin{array}{l}\text { Slightly } \\
\text { reduced }\end{array}$ & Normal & Normal \\
\hline Prednisone & $2.5 \mathrm{mg} \mathrm{q} 2 \mathrm{~d}$ & - & - & $5 \mathrm{mg} \mathrm{q} 2 \mathrm{~d}$ \\
\hline
\end{tabular}

centrations, reticulocyte counts, red cell indices, and marrow morphology and therefore served as useful controls. None were bleeding, and none were on prednisone. This study was approved by The Hospital for Sick Children Human Experimentation Committee.

Cultures. Erythroid colonies were grown as originally described (9) with some modification. $3 \mathrm{ml}$ of bone marrow was aspirated in a dry syringe and transferred to $5 \mathrm{ml}$ of supplemented Eagle's minimum essential medium (Grand Island Biological Co., Grand Island, N. Y.), $2 \%$ fetal calf serum, and $10 \mathrm{U} / \mathrm{ml}$ of preservative-free heparin. After centrifugation, the supernate was discarded, and the cells were resuspended in the same solution without heparin and recentrifuged. Buffy coat was removed and suspended in Eagle's medium in a final concentration of $1 \times 10^{7} \mathrm{nu}-$ cleated cells $/ \mathrm{ml}$.

The following were combined: $0.7 \mathrm{ml}$ bovine serum albumin (Miles Laboratories Inc., Elkhart, Ind.) ; $0.7 \mathrm{ml}$ beef embryo extract (Grand Island Biological Co.) ; $0.7 \mathrm{ml} \mathrm{L}$ asparagine (Sigma Chemical Co., St. Louis, Mo.); $1.4 \mathrm{ml}$ NCTC-109 (Microbiological Associates, Bethesda, Md.); and $2.1 \mathrm{ml}$ fetal calf serum. From this mixture, $0.8 \mathrm{ml}$ was placed into five separate tubes. To each tube was added $0.1 \mathrm{ml}$ of the cell suspension containing $1 \times 10^{\circ} \mathrm{nu}-$ cleated cells and $0.1 \mathrm{ml}$ EPO in varying concentrations so that the final culture concentrations were: $0.5,1.0,2.0$ and $2.5 \mathrm{U} / \mathrm{ml}$. EPO was obtained from anemic sheep plasma (Connaught Laboratories, Toronto, Canada) and had a potency of $2.8-4.7 \mathrm{U} / \mathrm{mg}$ dry weight (step III). It was reconstituted with NCTC-109 and frozen until used. NCTC109 without EPO was added to the last tube. Finally, 0.1 $\mathrm{ml}$ of bovine plasma was added to each tube, mixed with the contents, and, before clotting, plated rapidly into the wells of plastic titration plates (Linbro Chemical Co., New Haven, Conn.). Cultures were incubated at $37^{\circ} \mathrm{C}$ in air with $5 \% \mathrm{CO}_{2}$ in high humidity.

After 7-8 days of incubation, the plasma clots were removed from the wells and placed on microscope slides. Filter paper was placed over the clots and, by rolling with a pipette, the clots were flattened. The clots were fixed in
$5 \%$ glutaraldehyde in $0.01 \mathrm{M}$ phosphate buffer for $10 \mathrm{~min}$, washed in distilled water for $10 \mathrm{~min}$, and dried in an air stream. The slides were stained in 1\% 3,3-dimethoxybenzidine (Eastman Kodak Co., Rochester, N. Y.) in methanol for $3 \frac{1}{2} \mathrm{~min}$, then in $3 \%$ hydrogen peroxide in $70 \%$ ethanol for $1 \mathrm{~min}$. After rinsing in distilled water, they were counterstained with Harris' hematoxylin for $2 \mathrm{~min}$, airdried, and mounted with cover slips.

The clots were scanned at $100 \times$ magnification and the total number of colonies per clot was counted. A colony was defined as a clump of eight or more nucleated cells showing a positive brown-orange benzidine reaction. All determinations were done in quadruplicate and the results averaged. The counts were expressed as number of colonies per $1 \times 10^{5}$ nucleated cells plated. To determine the reproducibility of the colony assay, the results of the quadruplicate values in the control marrows at each EPO dosage were subjected to an analysis of variance (11). To compare colony size the numbers of cells in 100 colonies from each of the patients and four controls were counted.

Marrows from patients 1 and 2 were also cultured in methylcellulose for granulocyte colonies by a modification of the original method (12). Cultures contained conditioned medium (CSA) prepared from peripheral blood leukocytes of a normal adult. Results were expressed as number of colonies per $1 \times 10^{5}$ nucleated cells plated.

Mixing experiments. To detect the presence of a serum inhibitor to either EPO or erythroid progenitors, a control marrow was cultured in the presence of sera from patients 2 , 3 , and 4, which substituted for fetal calf serum. Serum from patients 3 and 4 was cultured with autologous marrow. To demonstrate the culture system is capable of detecting an inhibitor, autologous and control marrow was cultured in the presence of serum from an adult with acquired pure red cell aplasia who has a documented inhibitor to erythropoiesis (13). Normal human AB serum was used as control. To test sera from other anemic patients, control marrow was cultured with sera from two children with constitutional Fanconi's aplastic anemia treated by transfusion 
TABLE II

Erythroid Colony Growth in 30 Control Marrows

\begin{tabular}{crccc}
\hline & \multicolumn{4}{c}{ Erythroid colonies } \\
\cline { 2 - 5 } EPO & Mean & Range & SD & SE \\
\hline$U / m l$ & & & & \\
0.0 & 2 & $0-11$ & & \\
0.5 & 94 & $12-266$ & \pm 73 & \pm 14 \\
1.0 & 134 & $16-349$ & \pm 83 & \pm 16 \\
2.0 & 158 & $25-293$ & \pm 70 & \pm 14 \\
2.5 & 158 & $31-317$ & \pm 79 & \pm 15 \\
\hline
\end{tabular}

$1 \times 10^{5}$ marrow cells/culture; 7 -day incubation.

alone who had hemoglobin levels comparable to patients 2 and 3.

\section{RESULTS}

Individual colonies could be readily identified microscopically due to the orange-brown benzidine staining properties of the erythroid cells. Colony size ranged from 8 to over 100 nucleated cells. Clusters of less than eight nucleated cells, as well as single cells, were also seen but were not included in the counting. Cellular detail was distorted, and even when the erythroid characteristics were unmistakable, the stage of cellular maturation could not be judged accurately. Generally, the younger erythroids had larger, lighter-staining nuclei and had a fainter cytoplasmic benzidine stain. Macrophage colonies were also present and could easily be distinguished.

A preliminary time-course study for the appearance of erythroid colonies indicated that significant numbers first appeared on day 3 , reached a peak on day 7 , and then declined. In another experiment using a control marrow, increasing the number of nucleated marrow cells from $1 \times 10^{4}$ to $1 \times 10^{5}$ per culture resulted in a linear increase in erythroid colonies. Results of increasing the EPO concentration in $\mathbf{3 0}$ control marrows are shown in Table II. Without EPO there was almost no colony

TABLE III

Erythroid Colony Growth in Congenital Hypoplastic Anemia

\begin{tabular}{crrrr}
\hline & \multicolumn{4}{c}{ Erythroid colonies } \\
\cline { 2 - 5 } EPO & Pt 1 & Pt 2 & Pt 3 & Pt 4 \\
\hline$U / m l$ & & & & \\
0.0 & 0 & 0 & 0 & 0 \\
0.5 & 0 & 6 & 10 & 25 \\
1.0 & 0 & 10 & 20 & 53 \\
2.0 & $*$ & 16 & 32 & 91 \\
2.5 & 195 & 24 & 26 & 25 \\
\hline
\end{tabular}

$1 \times 10^{5}$ marrow cells/culture; 7-day incubation.

* Contaminated. formation; by adding EPO, the number of colonies increased linearly and then plateaued between 1.0 and 2.5 $\mathrm{U} / \mathrm{ml}$. Higher concentrations of sheep EPO resulted in a decrease in colony numbers. The range of colony counts was very wide at all EPO doses from patient to patient. Statistical analysis of the studies in the control marrows indicated that variations in the quadruplicate readings were not significant. Therefore, the assay is reproducible at each EPO concentration. Erythroid colony numbers did not correlate with the number of morphologically recognizable nucleated red cells plated. Optimum culture conditions $\left(1 \times 10^{5}\right.$ cells/culture, 2.5

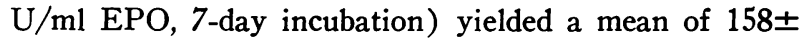
79 erythroid colonies per $1 \times 10^{5}$ nucleated marrow cells.

The number of erythroid colonies per $1 \times 10^{5} \mathrm{nu}-$ cleated cells cultured in the four children with congenital hypoplastic anemia is shown in Table III. Marrow from patient 1 had no colony growth in cultures containing up to $1.0 \mathrm{U} / \mathrm{ml} \mathrm{EPO}$. At $2.5 \mathrm{U} / \mathrm{ml}$ there were normal numbers. The cultures at $2.0 \mathrm{U} / \mathrm{ml}$ were contaminated. Marrow from patient 2 had colony growth at all EPO concentrations but the numbers were consistently lower than normal. Patient 3 had colony growth in all EPO-containing cultures just at or below the lower normal limit. Patient 4 had normal colony growth in all cultures except for that with $2.5 \mathrm{U} / \mathrm{ml}$, where the number was below normal. Colonies were of similar size to those of controls.

Results of studies to detect serum inhibitors are shown in Figs. 1 and 2. There was no decrease in colonies at the serum concentrations tested. In the two studies using autologous marrow some increase in colony growth resulted ; in patient 3 , colony numbers increased to normal levels in the autologous serum cultures.

Table IV summarizes studies of serum from the patient with acquired pure red cell aplasia. Erythroid colony growth was absent in the presence of the test serum. Normal human AB serum resulted in normal numbers of colonies. Sera from the patients with Fan-

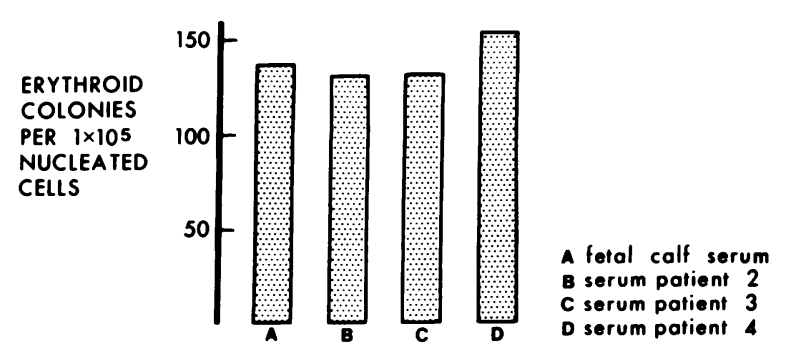

FIGURE 1 Effect of patient's sera on colony growth from a control marrow; $1 \times 10^{5}$ marrow cells/culture; $2.0 \mathrm{U} / \mathrm{ml}$ erythropoietin; 7-day incubation; final human serum concentration, $30 \%$. 


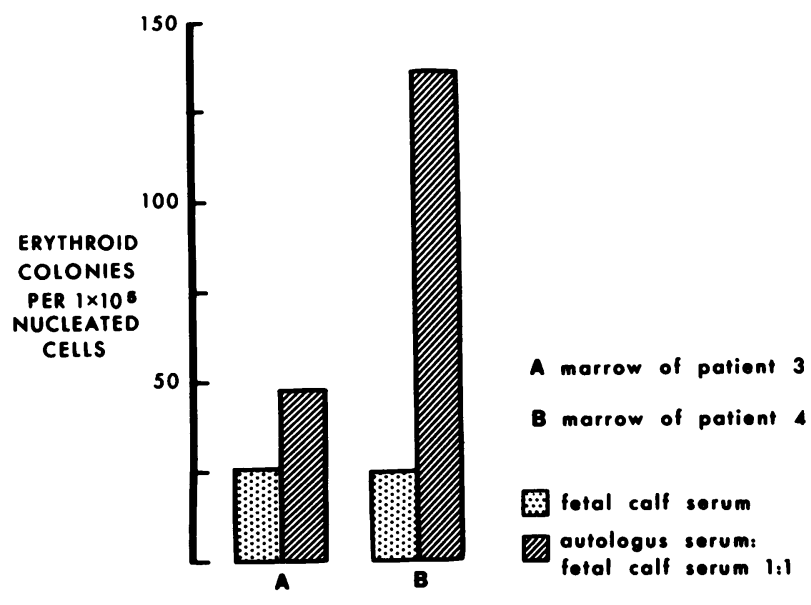

Figure 2 Effect of patients' sera on colony growth from autologous marrow; $1 \times 10^{5}$ marrow cells/culture; $2.5 \mathrm{U} /$ $\mathrm{ml}$ erythropoietin; 7-day incubation; final human serum concentration, $15 \%$.

coni's aplastic anemia resulted in colony numbers of 199 and $149 / 1 \times 10^{5}$ compared to the fetal calf serum control of $137 / 1 \times 10^{5}$.

Granulocyte colonies from marrows of patients 1 and 2 were normal to increased with 30 and $171 / 1 \times 10^{5}$ nucleated marrow cells, respectively. Normal values of 60 studies in our laboratory are $48 \pm 34 / 1 \times 10^{5}$ marrow cells.

\section{DISCUSSION}

The etiology and pathogenesis of congenital hypoplastic anemia has not been adequately explained. Prenatal factors seem to be operative in most patients since anemia is often present at birth, there is an increased incidence of congenital malformations, and sibling involvement suggests a genetic influence (14). There is little evidence to suggest that maternal-fetal isoimmune problems, maternal drug ingestion, fetal chromosomal abnormalities, or intrauterine infections play a role in the etiology. The theory that a disturbance of tryptophan metabolism was responsible for the anemia (15)

TABLE IV

Mixing Experiments in Acquired Red Cell Aplasia

\begin{tabular}{lcc}
\hline & \multicolumn{2}{c}{ Marrow source } \\
\cline { 2 - 3 } Serum source & Autologous & Control \\
\hline & \multicolumn{2}{c}{ Colonies $/ 1 \times 10^{5}$ cells } \\
Normal AB & 96 & 195 \\
Patient & 0 & 0 \\
\hline
\end{tabular}

EPO, $2.0 \mathrm{U} / \mathrm{ml} ; 1 \times 10^{5}$ cells/culture, 7-day incubation; final human serum concentration, $30 \%$. lost favor when it was demonstrated that abnormal excretion of tryptophan metabolites occurs in a variety of anemias and is nonspecific (16).

Since EPO levels are consistently elevated in children with congenital hypoplastic anemia (2), it is logical to study the marrow erythroid line to see if the mechanism of end-organ failure can be clarified. The earliest morphologically identifiable erythroid element is the pronormoblast; however, there are precursors present in marrow that cannot be identified by traditional morphologic methods. A current and widely held concept of erythropoiesis is that erythroid differentiation begins with a single pluripotent stem cell, moves through a unipotent EPO-responsive or "committed" stem cell, and ends as a cohort of hemoglobin-producing erythrocytes (17). Studies of early events in erythropoiesis have been facilitated by the introduction of a tissue culture method for growth of erythroid colonies $(9,10)$. There is cogent evidence that these colonies are in the erythroid line. They grow in response to added EPO, the hormone that controls production of erythrocytes (18); without EPO, there is almost no growth. The individual cells stain positively with benzidine, which is specific for hemoglobin, and they morphologically resemble nucleated red cells.

The argument that each colony represents a more primitive precursor than the pronormoblast is supported by three lines of documentation. Firstly, recognizable erythroids and colony-forming cells can be separated by velocity sedimentation (10), implying that the cells are different sizes. Secondly, our data indicate that there is no statistical relationship between percentage of recognizable erythroids plated and numbers of colonies grown. Finally, colonies developed from marrows of patients 2 and 3 , both of whom had no recognizable erythroids at the time of study.

Since the marrows from all four patients with congenital hypoplastic anemia gave rise to erythroid colonies, the study demonstrated that these children had erythroid precursors which were capable of proliferation and differentiation. However, there may have been a quantitative problem in erythropoiesis. The marrows from the two children not taking prednisone (patients 2 and 3 ) produced erythroid colony numbers in the lowest normal or below normal range at all EPO doses.

From the data we cannot entirely exclude a reduced absolute number of erythroid stem cells in this condition. However, we feel that a defective response to EPO by a normal number of erythroid precursors is also a possibility. We have been unable to test very large doses of sheep EPO on our patients' marrows because of the inhibitory effect of EPO concentrations greater than $2.5 \mathrm{U} / \mathrm{ml}$, possibly due to impurities in the commercial preparation. It would be important to demonstrate that 
the defect is intrinsic to the stem cell because of the therapeutic possibility of using bone marrow transplantation in patients unresponsive to prednisone. The action of prednisone in this disorder is completely unclear. It is effective clinically and colony numbers were greater from the marrows of the two prednisone-treated patients. Unfortunately serial studies of these patients were not possible.

Mixing experiments failed to reveal any serum inhibitor of EPO or erythroid precursors at the serum concentrations used, with either autologous marrow or control marrow. It is impossible to use final concentrations of serum greater than $30 \%$ without impairing the tissue culture system; therefore, the presence of weak inhibitors could be missed. The method seems to be capable of detecting a serum inhibitor, as serum from the adult with acquired red cell aplasia strikingly reduced colony growth from autologous and control marrow. This contrasts with the results in the congenital variety and suggests that the mechanism of the two disorders may be different. Normal human AB serum did not have this effect, indicating culture conditions remained adequate. No inhibition was seen with serum from the two children with Fanconi's anemia and in one there was increased colony growth. Inhibition at a cellular level cannot be ruled out but is unlikely as the patients' marrows did form colonies in vitro.

\section{ACKNOWLEDGMENTS}

This study was supported by a Medical Research Council grant (MA-4982).

\section{REFERENCES}

1. Allen, D. M., and L. K. Diamond. 1961. Congenital (erythroid) hypoplastic anemia. Am. J. Dis. Child. 102: 416-423.

2. Hammond, D., and G. Keighley. 1960. The erythrocytestimulating factor in serum and urine in congenital hypoplastic anemia. Am. J. Dis. Child. 100: 466-468. (Abstr. and discussion)

3. Krantz, S. B., and V. Kao. 1967. Studies on red cell aplasia. I. Demonstration of a plasma inhibitor to heme synthesis and an antibody to erythroblast nuclei. Proc. Natl. Acad. Sci. U. S. A. 58: 493-500.

4. Krantz, S. B., and V. Kao. 1969. Studies on red cell aplasia. II. Report of a second patient with an antibody to erythroblast nuclei and a remission after immunosuppressive therapy. Blood. 34: 1-13.

5. Krantz, S. B. 1972. Studies on red cell aplasia. III. Treatment with horse antihuman thymocyte gamma globulin. Blood. 39 : 347-360.

6. Safdar, S. H., S. B. Krantz, and E. B. Brown. 1970. Successful immunosuppressive treatment of erythroid aplasia appearing after thymectomy. Br. J. Haematol. 19: 435-443.

7. Krantz, S. B., W. H. Moore, and S. D. Zaentz. 1973. Studies on red cell aplasia. V. Presence of erythroblast cytotoxin in $\gamma \mathrm{G}$-globulin fraction of plasma. J. Clin. Invest. 52: 324-336.

8. Zaentz, S. D., and S. B. Krantz. 1973. Studies on pure red cell aplasia. VI. Development of two-stage erythroblast cytotoxicity method and role of complement. $J$. Lab. Clin. Med. 82 : 31-43.

9. Stephenson, J. R., A. A. Axelrad, D. L. McLeod, and M. M. Shreeve. 1971. Induction of colonies of hemoglobin-synthesizing cells by erythropoietin in vitro. Proc. Natl. Acad. Sci. U. S. A. 68: 1542-1546.

10. Tepperman, A. D., J. E. Curtis, and E. A. McCulloch 1974. Erythropoietic colonies in cultures of human marrow. Blood. 44: 659-669.

11. Armitage, P. 1973. Statistical Methods in Medical Research. Blackwell Scientific Publications, London. 226232.

12. Iscove, N. N., J. S. Senn, J. E. Till, and E. A. McCulloch. 1971. Colony formation by normal and leukemic human marrow cells in culture: Effect of conditioned medium from human leukocytes. Blood. 37: 1-5.

13. Browman, G. P., M. H. Freedman, M. A. Blajchman, and J. A. McBride. 1974. An erythropoietic inhibitor acting at the "stem cell" level in refractory anemia. Clin. Res. 22: 742A. (Abstr.)

14. Diamond, L. K., D. M. Allen, and F. B. Magill. 1961. Congenital (erythroid) hypoplastic anemia. A 25-year study. Am. J. Dis. Child. 102: 403-415.

15. Altman, K. I., and G. Miller. 1953. A disturbance of tryptophan metabolism in congenital hypoplastic anaemia. Nature (Lond.). 172: 868.

16. Hankes, L. V., R. R. Brown, L. Schiffer, and M. Schmaeler. 1968. Tryptophan metabolism in humans with various types of anemias. Blood. 32: 649-661.

17. Erslev, A. J. 1972. Production of erythrocytes. In Hematology. W. J. Williams, E. Beutler, A. J. Erslev, and R. W. Rundles, editors. McGraw-Hill Book Company, New York. 162-177.

18. Jacobson, L. O., E. Goldwasser, and C. W. Gurney. 1960. Transfusion-induced polycythaemia as a model for studying factors influencing erythropoiesis. In Ciba Foundation Symposium on Haemopoiesis. Cell Production and Its Regulation. G. E. W. Wolstenholme and M. O’Conner, editors. Little, Brown \& Co., Boston. 423-452. 